\title{
An empirical analysis of cigarette demand in Argentina
}

\author{
Eugenio Martinez, ${ }^{1}$ Raul Mejia, ${ }^{2}$ Eliseo J Pérez-Stable ${ }^{3}$
}

\begin{abstract}
- Additional data are published online only. To view this file please visit the journal online (http://dx.doi.org/10. 1136/tobaccocontrol-2012050711)

${ }^{1}$ Instituto de Estudios Laborales y del Desarrollo Económico (IELDE) and Consejo de Investigaciones de la Universidad Nacional de Salta (CIUNSa), Facultad de Ciencias Económicas, Universidad Nacional de Salta, Salta, Argentina

${ }^{2}$ Centro de Estudios de Estado y Sociedad and Programa de Medicina Interna General, Universidad de Buenos Aires, Buenos Aires, Argentina ${ }^{3}$ Division of General Internal Medicine, Department of Medicine, Medical Effectiveness Research Center for Diverse Populations, Helen Diller Family Comprehensive Cancer Center, University of California, San Francisco, California, USA
\end{abstract}

\section{Correspondence to} Professor Eliseo J Pérez-Stable, 1545 Divisadero Street, Box 0320 San Francisco, CA 94143-0320, USA; eliseops@medicine.ucsf.edu

Received 1 August 2012 Accepted 5 May 2013 Published Online First 12 June 2013

\section{ABSTRACT \\ Objective To estimate the long-term and short-term effects on cigarette demand in Argentina based on changes in cigarette price and income per person $>14$ years old.}

Method Public data from the Ministry of Economics and Production were analysed based on monthly time series data between 1994 and 2010. The econometric analysis used cigarette consumption per person

$>14$ years of age as the dependent variable and the real income per person $>14$ years old and the real average price of cigarettes as independent variables. Empirical analyses were done to verify the order of integration of the variables, to test for cointegration to capture the long-term effects and to capture the short-term dynamics of the variables.

Results The demand for cigarettes in Argentina was affected by changes in real income and the real average price of cigarettes. The long-term income elasticity was equal to 0.43 , while the own-price elasticity was equal to -0.31 , indicating a $10 \%$ increase in the growth of real income led to an increase in cigarette consumption of $4.3 \%$ and a $10 \%$ increase in the price produced a fall of $3.1 \%$ in cigarette consumption. The vector error correction model estimated that the short-term income elasticity was 0.25 and the short-term own-price elasticity of cigarette demand was -0.15 . A simulation exercise showed that increasing the price of cigarettes by $110 \%$ would maximise revenues and result in a potentially large decrease in total cigarette consumption. Conclusion Econometric analyses of cigarette consumption and their relationship with cigarette price and income can provide valuable information for developing cigarette price policy.

\section{INTRODUCTION}

Tobacco use has become the leading cause of preventable death in the world with nearly six million deaths per year and hundreds of billions of dollars of economic losses. If current trends continue, by 2030 tobacco will kill more than eight million people worldwide each year, with $80 \%$ occurring in low-income and middle-income countries (LMIC). ${ }^{1}$ Argentina is a middle-income country that is among the 10 leading tobacco-growing countries in the world and second in Latin America after Brazil. ${ }^{2}$ Smoking prevalence in Argentina was $38.3 \%$ for men and $24.5 \%$ for women in $2001,{ }^{3}$ but by 2009 , smoking prevalence had declined to $32.4 \%$ and $22.4 \%$ for men and women, respectively. ${ }^{4}$ Conte Grande ${ }^{5}$ estimated that there were 41280 deaths attributable to tobacco consumption in Argentina among persons older than 35 years in 2003 which generated a cost by loss of future earnings from premature death of $\$ 543$ million pesos in 2003.

Some studies suggest that LMIC could reduce 115 million smoking-related deaths by 2050 using a combination of tax increases, advertising bans, informational campaigns, restrictions on smoking in public places and enhanced tobacco dependence treatments. ${ }^{6}$ Evidence on the health and economic consequences of tobacco use has led many governments, first in high-income countries and more recently in a growing number of LMIC, to significantly increase tobacco taxes to reduce tobacco use. There are few studies that have evaluated the effect of tobacco taxes on cigarette demand in Latin America and only one study that explored the demand for cigarettes in Argentina. ${ }^{7}$ There is currently approved legislation in Argentina that is pending implementation which will prohibit smoking in all indoor public places, prohibit the sale of tobacco products to minors and greatly restrict tobacco advertising. However, proposals to increase taxes on cigarettes have not advanced.

Elasticity is an economic measure that captures the sensitivity of the quantity demanded of a good (cigarettes) with respect to a change in its price. Under normal circumstances, there is an inverse relationship, so when cigarettes are more expensive demand decreases and price elasticity is reported as a negative value. The per cent change in demand for cigarettes as a consequence of price change defines the concept of price elasticity. Income elasticity reflects the ability of the population to purchase the product as per capita income changes. The usual relationship is in a positive direction with capacity to purchase, or demand, increasing as per capita income increases. Analysing and predicting the evolution of cigarette demand are useful in developing an effective tobacco control policy. This paper approaches the problem from an econometric perspective using data from a middle-income country with no plan to increase taxes on cigarettes. Our goal was to conduct an empirical analysis of cigarette demand in Argentina over the period 1994-2010 and to estimate income and price elasticities, which are two factors that drive demand for cigarettes.

\section{Tobacco market in Argentina}

The tobacco industry in Argentina is led by two subsidiaries of multinationals Massalin Particulares S.A. of Phillips Morris Co and Nobleza Picardo of British American Tobacco with $97.3 \%$ of the national cigarette market. The provinces of Jujuy, Misiones and Salta produced $92 \%$ of the tobacco in the country and there has been a $30 \%$ increase in land use for cultivation between 1990 and 
$2009 .^{8}$ The economic activity of tobacco farming and production is labour-intensive and generates almost 53840 jobs. $^{9}$

Tobacco production in Argentina is subsidised through payment to the producer as an overprice on the final cost of storing. In order to finance this overprice, the national government collects the Special Tobacco Fund (Fondo Especial de Tabaco or FET) through a specific tax on consumption of $7 \%$ and about $80 \%$ of this fund is distributed back to the tobacco producers as a state subsidy. The final price of cigarettes in retail markets includes a complex set of different types of taxes that add up to about $70 \%$ of the price. ${ }^{7}$

The average real retail price per pack of cigarettes in pesos was stable between January 1994 and December 1999, but since then there have been wide fluctuations from a minimum of $\$ 1.50$ in March 2003 to a maximum of $\$ 3.32$ in October 2010 (figure 1). The monthly average consumption of cigarettes per person in Argentina for those older than 14 years of age was 126 from 1994 to 2001 and decreased after 2001 to 116 . Cigarette consumption in Argentina remains high, but after steadily decreasing from 1994 to 2001 consumption has levelled somewhat at a rate lower than in the 1990s. ${ }^{10}$

\section{METHODS}

\section{Data sets}

This analysis used the available monthly economic data from Argentina from January 1994 to December 2010. All the variables were seasonally adjusted. Cigarette consumption data were derived from total sales of cigarettes to the public reported by the Ministry of Economics and Production on a monthly basis. No population surveys were available to ascertain cigarette consumption on an individual level. Income data used the gross domestic product (GDP) per person older than 14 years; the price variable was determined by the average price of cigarettes sold to the public that included taxes. Income and price data were adjusted for inflation using the consumer price index. All data except population data were obtained from the Ministry of Economics and Production in Argentina. The population data were collected from the Instituto Nacional de Estadisticas y Censo (INDEC or National Institute of Statistics and Census). ${ }^{11}$ Population statistics for estimates of persons older than 14 years were only available annually, and thus were assumed to be a constant growth rate in order to obtain monthly estimates (see online supplementary table A1).

\section{Methodological framework}

Much of the empirical literature related to estimates of cigarette demand with time series use a double-logarithmic specification because of the simplicity of obtaining the elasticity under study. After confirming this functional approach as appropriate (see online supplementary section 1), a linear double-logarithmic form using consumption as a dependent variable and income, price and some dummy variables as independent variables was used in the empirical analysis. Therefore, in the empirical study the following specification for the long-term demand for cigarettes was employed:

$$
\ln \left(\mathrm{Qpc}_{\mathrm{t}}\right)=\alpha_{0}+\alpha_{1} \ln \left(\mathrm{RYpc}_{\mathrm{t}}\right)+\alpha_{2} \ln \left(\mathrm{RP}_{\mathrm{t}}\right)+\alpha_{3} \mathrm{D}_{\mathrm{t}}+\mu_{\mathrm{t}}
$$

where $\mathrm{Qpc}_{\mathrm{t}}$ is the quantity of cigarettes consumed and was measured as numbers of cigarettes per person older than 14 years; $\mathrm{RYpc}_{\mathrm{t}}$ is the real income measured as the real GDP in real terms per person older than 14 years, $R P_{t}$ is the real average price of cigarettes, $\alpha$ is constant term, $D_{t}$ is a group of dummy variables and $\pi_{\mathrm{t}}$ is an error term. The first dummy variable $(D($ age $))$ accounts for the introduction of a ban on sales for persons under 18 years old (March 1997). The second dummy variable $(D($ control $))$ represents the implementation of tobacco control measures such as smoke-free places (with a value of 1 between January 2006 and December 2010, and 0 in all other months). The last dummy variable (Dummy 02) represents a change in the macroeconomic policies (March 2002) to capture any effects of the country's economic crisis in 2001-2002 on cigarette consumption as a consequence of the devaluation of the peso.

In the empirical analysis, we tested for the existence of a longterm equilibrium relationship among the variables (estimation of Equation 1), while the use of the vector error correction model (VECM) captured the short-term dynamics of the variables (see online supplementary section 2, Table A2).

The presence of cointegration among the variables will show the long-term equilibrium relationship described above. VECM represents the short-term movements in the variables. When the error correction term is included in the model, the long term,
Figure 1 Average monthly consumption and real retail price of cigarettes-Argentina 1994:12010:12. The top line shows the average monthly consumption of cigarettes from 1994 to 2010. The bottom line shows the average price of one pack of 20 cigarettes during these years.

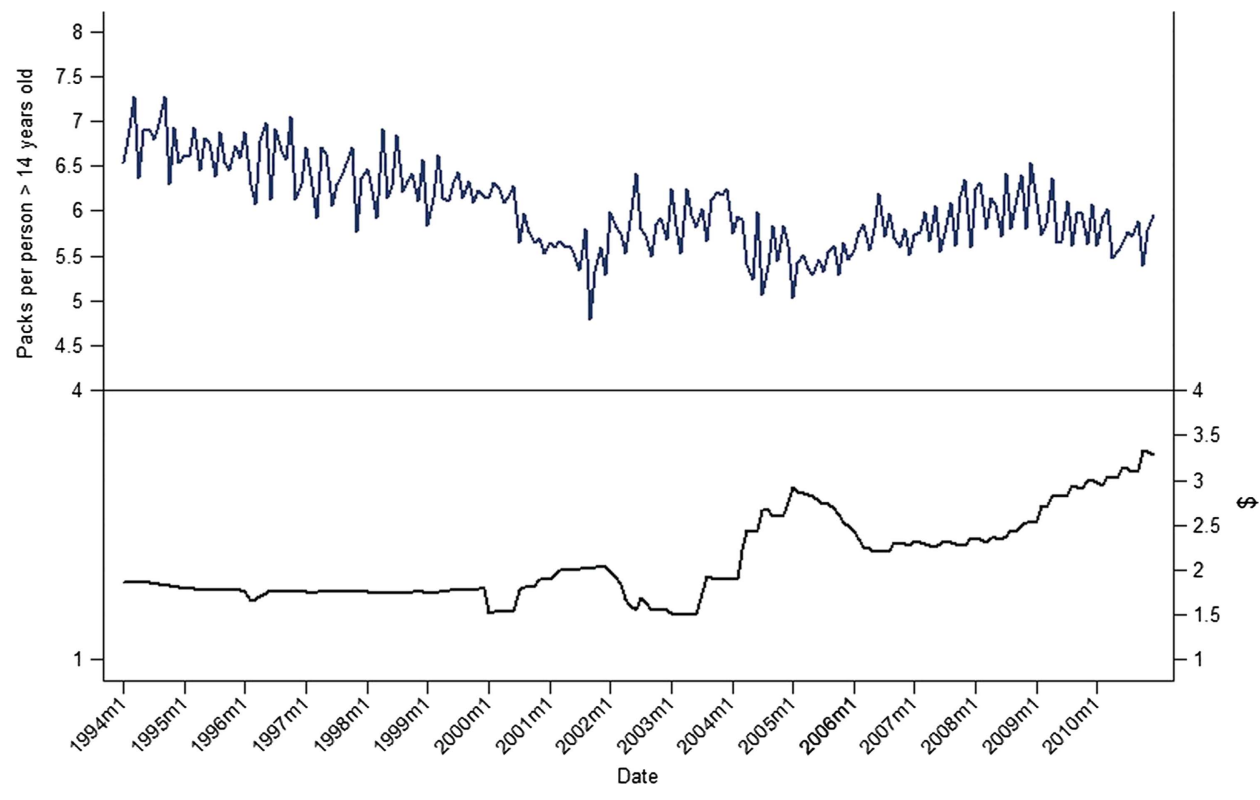

Martinez E, et al. Tob Control 2015;24:89-93. doi:10.1136/tobaccocontrol-2012-050711 
or equilibrium stable, relations are accounted for. The Johansen test result implied that there was one cointegration vector among cigarette consumption, income and price (see online supplementary section 3 , table A3).

Having verified that a cointegrating relationship existed between the variables, VECM was applied. The error correction term measures the proportion by which the long-term imbalance in the dependent variable is corrected in each short-term period. The size and the statistical significance of the error correction term measure the extent to which each dependent variable has the tendency to return to its long-term equilibrium.

\section{SIMULATION MODEL}

We applied the elasticity values derived from the empirical analysis in a simulation model following the example by $\mathrm{Hsieh}^{12}$ to show the possible impact of increasing the final price of cigarettes on consumption and on revenue from cigarette tax. The initial values for the simulation corresponded to the last quarter of the year 2010. We used 1 month to define short-term time period because we measured the effect on consumption at 30 days of price increase. We used 3 months as long-term time period because this was captured as the short-term dynamic in VECM with data from a rolling 3-month period (two lags or two previous months) being used. The monetary values are in pesos as of December 2010 and the values correspond to the consumption of cigarettes and the revenue from cigarette tax from the last quarter of 2010. The tax increases were modelled as completely transferring to the final retail prices.

\section{RESULTS}

The estimated long-term (3 months) demand is summarised in the following equation:

$$
\begin{aligned}
\ln \left(\mathrm{Qpc}_{\mathrm{t}}\right)=- & 2.15+0.43 \ln \left(\mathrm{RYpc}_{\mathrm{t}}\right)-0.31 \ln \left(\mathrm{RP}_{\mathrm{t}}\right) \\
& (5.75)(7.65) \quad(-2.60) \\
- & 0.10 \mathrm{D}(\text { age })-0.05 \mathrm{D}(\text { control }) \\
& (-11.22) \quad(-2.91)
\end{aligned}
$$

where the numbers in parentheses contain the t-statistics. Both coefficients are significant with signs in the expected direction and because we used a double-logarithmic function, the coefficients of the income and price variables represent the long-term elasticity of each. Therefore, the long-term income elasticity was equal to 0.43 and the long-term price elasticity was equal to -0.31 , meaning a $10 \%$ increase in income will produce an increase in cigarette consumption by $4.3 \%$ and a $10 \%$ increase in price will produce a decrease by $3.1 \%$ in cigarette consumption.

\section{Short-term relationship}

In the restricted dynamic cigarette demand presented in table 1, all the estimated coefficients, including the error correction term, are statistically significant and have a sign in the expected direction. The error correction term is equal to -0.82 suggesting that the speed of adjustment is equal to $82 \%$. This means that after the deviation from the steady state, the model adjusts at a rate of $82 \%$ in the direction of long-term equilibrium once again. The estimated coefficient for the short-term change of real income is positive and significant and its value is equal to 0.25 . This value implies that a $10 \%$ increase in the growth of real income will lead to an increase in cigarette consumption by $2.5 \%$ in the short
Table 1. Short-term relationship*

\begin{tabular}{lcr}
\hline Variable & Coefficient & t Value \\
\hline const & 0.08 & 6.17 \\
$\Delta \ln (\mathrm{RP})_{(-1)}$ & -0.15 & -7.16 \\
$\Delta \ln (\mathrm{RP})_{(-2)}$ & -0.08 & -076 \\
$\Delta \ln (\mathrm{Qpc})_{(-1)}$ & -016 & -2.14 \\
$\Delta \ln (\mathrm{Qpc})_{(-2)}$ & -0.56 & -9.31 \\
$\Delta \ln (\mathrm{RYpc})_{(-1)}$ & 0,25 & 2.38 \\
$\Delta \ln (\mathrm{RYpc})_{(-2)}$ & 0,15 & 0.71 \\
$\mathrm{D}($ age $)$ & -0.08 & -5.98 \\
$\mathrm{D}(\mathrm{control})$ & -0.03 & -3.82 \\
Error correction term & -0.82 & -8.11 \\
$\mathrm{R}^{2}=0.57$ & & \\
F-statistic $=30.53$ & & \\
DW-test $=1.97$ & & \\
ARCH test $=0.72$ & & \\
White heteroskedasticity =0.59 & \\
\hline *Only the restricted error correction equation for cigarette demand is presented. All \\
other equations are available from the authors upon request.
\end{tabular}

term. The estimated coefficient for the short-term effect of the price is statistically significant and is equal to -0.15 . This coefficient can be interpreted as the short-term own-price elasticity of cigarette demand. That means a $10 \%$ increase in the price producing a fall of $1.5 \%$ in cigarette consumption.

The coefficient of the dummy variable $D($ age), which captured the effect of the prohibition on cigarette sales to persons under 18 years old was statistically significant and with a negative sign. A similar result was obtained for the dummy $D$ (control), which suggests that these tobacco control policies decrease tobacco consumption.

\section{Simulation model}

The results of the simulation model are shown in table 2. The initial values for the last quarter of the year 2010 are shown in the 'Status quo' column and the remaining columns contain information about seven different increases in the final price of cigarettes. The complete simulation that shows the impact of all price increases from $0 \%$ (status quo) to $320 \%$ is shown in online supplementary figure A1.

From the simulation, we can obtain important information for tobacco control policies. An increase in the final price of $20 \%$ can lower the total consumption of cigarette packs by 34.38 million in a quarter and can also generate an increase in the fiscal revenue from cigarette tax of $\$ 282.55$ million. On the other hand, a bigger increase in price, for example, of $50 \%$ generated a fall in the consumption of cigarettes per person $>14$ years old of 2.82 packs quarterly and an increase of $\$ 602.02$ million pesos in tax revenue. Increasing the price by $110 \%$ will produce the maximum cigarette tax revenue and the greatest decrease in total consumption of cigarettes (table 2).

\section{DISCUSSION AND POLICY IMPLICATIONS}

This paper examined cigarette demand in Argentina employing monthly data over the period 1994-2010. Cointegration techniques were applied to estimate both long-term and short-term income and own-price elasticity of demand for cigarettes. Finally, the importance of short-term deviations was presented using VECM estimation. The empirical results suggest that in 
Table 2 Simulation of alternative increases in cigarette retail price by increased taxes using quarterly data, Argentina, 2010

\begin{tabular}{|c|c|c|c|c|c|c|c|c|}
\hline & \multirow{3}{*}{$\begin{array}{l}\text { Status quo } \\
2010 \text { Q:4 }\end{array}$} & \multicolumn{7}{|c|}{ Long-term own-price elasticity= -0.31} \\
\hline & & \multicolumn{7}{|c|}{ Price increase } \\
\hline & & $10 \%$ & $20 \%$ & $30 \%$ & $40 \%$ & $50 \%$ & $60 \%$ & $110 \%$ \\
\hline A. Average retail price (\$) & 5.97 & 6.54 & 7.16 & 7.76 & 8.36 & 8.96 & 9.55 & 12.54 \\
\hline B. Average tax per pack (\$) & 4.06 & 4.47 & 4.87 & 5.28 & 5.68 & 6.09 & 6.50 & 8.53 \\
\hline C. Total cigarette consumption in millions of packs & 554.58 & 537.39 & 520.20 & 503.00 & 485.81 & 468.62 & 451.43 & 365.47 \\
\hline D. Changes in C (decrease) & - & $(17.19)$ & (34.38) & $(51.58)$ & $(68.77)$ & (85.96) & $(103.15)$ & (189.11) \\
\hline E. Cigarette consumption per person $>14$ years old (packs) & 18.18 & 17.62 & 17.05 & 16.49 & 15.93 & 15.36 & 14.80 & 11.98 \\
\hline F. Changes in $\mathrm{E}$ (decrease) & - & $(0.56)$ & $(1.13)$ & $(1.69)$ & $(2.25)$ & $(2.82)$ & $(3.38)$ & $(6.20)$ \\
\hline G. Revenue from cigarette tax in millions of pesos & 2251.59 & 2399.74 & 2534.15 & 2654.59 & 2761.08 & 2853.62 & 2932.19 & 3115.68 \\
\hline H. Changes in $\mathrm{G}$ & - & 148.14 & 282.55 & 403.00 & 509.49 & 602.02 & 680.59 & 864.08 \\
\hline
\end{tabular}

the long-term period (3 months) the demand for cigarettes was affected by changes in real income and real price. The value of income elasticity was equal to 0.43 , while the value of price elasticity was equal to -0.31 . The results of VECM estimation show that the income elasticity in the short term (1 month) in Argentina is equal to 0.25 and the short-term ( 1 month) price elasticity of the demand for cigarettes is -0.15 .

These income and price elasticity results for Argentina fall in between the elasticity estimates made for the other South American countries. Studies of elasticity estimates for cigarette demand in Bolivia for the period 1988-2002 found an income elasticity of 0.71 and an own-price elasticity of demand of $-0.85 .^{13}$ Data obtained from Brazil estimated that the price elasticity of cigarette demand for long term and short term were -0.42 and -0.25 , respectively, from 1991 to $2003 .{ }^{14}$ An innovative approach estimated income and own-price elasticity of cigarette demand in Chile comparing conventional models with the myopic addiction model. Using the conventional models of long-term demand elasticity, this was equal to 0.23 for income elasticity and -0.21 for own-price elasticity. ${ }^{15}$ When the authors applied the myopic addiction model, results for the long-term and short-term own-price elasticity were -0.45 and -0.22 , respectively, and results for the income elasticity were 0.22 and 0.11 , respectively. ${ }^{15}$ Analyses of the demand for legal cigarettes in Uruguay using quarterly time series for the period 1991-2003 showed a price elasticity of -0.55 for the long term and -0.49 for the short term; income elasticity values were 0.73 and 0.65 for the long term and short term, respectively. ${ }^{16}$

Argentina has undergone steady economic expansion with annual growth rates as high as 9\% since 2003. Despite this expected expansion of purchasing power, the price of cigarettes has remained stagnant and thus these economic policies may be counterproductive to tobacco control. Although smoking prevalence has decreased somewhat, the potential for greater impact by raising cigarette prices to keep up with per capita income has not been realised. Our estimates of elasticity provide valuable information for policy makers on the possible impact of an increase in final retail price of cigarettes (through a tax) on the amount smoked either by encouraging cessation, delaying initiation or decreasing the amount each smoker smokes (intensity). Raising the price of cigarettes simply to keep up with the expanded economic capacity of the population is recommended as a minimum measure based on these data. However, our results show there is a wide margin to increase the cigarette price without revenues from cigarette tax decreasing.
It is important that public health policy makers make their decisions using information from empirical studies based on their own country's data. Therefore, this paper makes a contribution in two ways by providing the estimation of income and price elasticity for Argentina and by addressing the gap caused by the lack of empirical information on cigarette demand in Argentina.

This policy of increasing cigarette prices through taxation is part of Article 6 of the Framework Convention from WHO that was signed but not ratified by Argentina. The results of the simulation exercise suggest that an increase in cigarette prices would permit the government to increase its revenues from taxes imposed on cigarettes to $38 \%$, while at the same time expecting a decrease in consumption. This would be achieved by raising the price by $110 \%$ or slightly more than twice the current price in Argentina.

The results of our analysis and the simulation model suggest that increases in cigarette prices by higher tax in Argentina can be an effective instrument for reducing tobacco consumption. Furthermore, the income elasticity estimates in the long term imply that a substantially higher cigarette consumption pattern would be expected as the real income of Argentineans converges with the income of the households from high-income countries. Finally, Argentina is currently working on different antismoking programmes and policies and trying to implement the Framework Convention from WHO even without formal legislative ratification. Policy makers and tobacco control advocates could benefit from the findings of this study that provides useful

\section{What this paper adds}

- Using available public data from the Ministry of Economics and Production of Argentina between 1994 and 2010, this econometric analysis showed that the demand for cigarettes was affected by changes in real income and the real average price of cigarettes.

- Using these values in a simulation exercise showed that increasing the price of cigarettes by $110 \%$ through additional taxes would both maximise government revenues and result in a potentially large decrease in total cigarette consumption. This would potentially lead to thousands of saved lives in future. 
information on the characteristics of the cigarette market in Argentina and supports proposals to increase taxes.

Acknowledgements We would like to thank Teh-wei Hu, PhD, and John Tauras, $\mathrm{PhD}$, for providing excellent comments and suggestions on earlier versions of this paper and Cecilia Populus-Eudave for research administrative support. The views expressed in this paper are solely those of the authors and do not necessarily reflect the views of the institutions.

Contributors The authors EM, RM and EJP-S meet the authorship conditions described below. Authorship credit should be based on (1) substantial contributions to conception and design, acquisition of data or analysis and interpretation of data; (2) drafting the article or revising it critically for important intellectual content; and (3) final approval of the version to be published.

Funding This work was supported by the Tobacco Research Network Programme, Fogarty International Center, National Institute on Drug Abuse and National Institutes of Health, USA. Grant number: TW05935.

\section{Competing interests None.}

Provenance and peer review Not commissioned; internally peer reviewed.

\section{REFERENCES}

1 World Health Organization. WHO report on the global tobacco epidemic, 2011: warning about the dangers of tobacco. Geneva: World Health Organization, 2011.

2 Eriksen M, Mackay J, Ross H. The Tobacco Atlas. Fourth edn. Atlanta, GA: American Cancer Society; New York, NY: World Lung Foundation, 2012:52.

3 Martínez E, Kaplan C, Guil V, et al. Smoking behavior and demographic risk factors in Argentina: a population-based survey. Prev Control 2006;2:187-97.

4 Ferrante D, Linetzky B, Konfino K, et al. 2009 National Risk Factors Survey: evolution of the epidemic of chronic non communicable diseases in Argentina. Cross sectional study. Rev Argent Salud Pública 2011;2:34-41.
5 Grand M Conte. Reestimación y actualización del costo económico en Argentina de la mortalidad atribuible al tabaco en adultos. CEMA Working Papers: Serie Documentos de Trabajo, 305. Buenos Aires, 2005.

6 Abascal W, Esteves E, Goja B, et al. Tobacco control campaign in Uruguay: a population-based trend analysis. The Lancet 2012;380:1575-82.

7 González-Rosada M. Economía del Control del Tabaco en los países del Mercosur y Estados Asociados. Argentina: 1996-2004. Washington: Organización Panamericana de la Salud, 2006.

8 Ministerio de Agricultura GyP. Evolucion de la Produccion Primaria de Tabaco (1986/1987-2010-2011). In: Minagri, ed. Programa de Reconversion de Areas Tabacaleras Buenos Aires, Argentina: Secretaria de Agricultura, Ganaderia y Pesca, 2011:36.

9 Corradini E, Zilocchi H, Cuesta R, et al. Caracterización del Sector Productor Tabacalero en la República Argentina. Serie Documentos de Investigación. Buenos Aires,: Universidad Católica Argentina de Buenos Aires, 2005.

10 González-Rosada M. Estudio sobre el Comercio Legal de Productos del Tabaco en Argentina. Estudio sobre el Comercio Legal de Productos del Tabaco en Argentina. Buenos Aires: Argentina Documento de Trabajo, Universidad Torcuato Di Tella, 2008.

11 INDEC. Estimaciones y Proyecciones de Población: Total del País. Serie Análisis Demográfico, No 30, 2004:1950-2015.

12 Hsieh CR, YS L. The economics of tobacco control in Taiwan. In: Abedian RVdM, Wilkins N, Jha P, eds. In the economics of tobacco control: towards an optimal policy mix, 1998:306-29.

13 Alcaraz V. Economía del Control del Tabaco en los países del Mercosur y Estados Asociados. Bolivia, Washington: Organización Panamericana de la Salud, 2006.

14 Iglesias R. A economia do controle do tabaco nos países do Mercosul e associados. Brasil, Washington: Organización Panamericana de la Salud., 2006.

15 Debrott D. Economía del Control del Tabaco en los países del Mercosur y Estados Asociados. Chile, Washington: Organización Panamericana de la Salud., 2006.

16 Ramos A. Economía del Control del Tabaco en los países del Mercosur y Estados Asociados. Uruguay, Washington: Organización Panamericana de la Salud., 2006. 